\title{
Especie nueva de Albizia (Leguminosae: Mimosoideae) de Centroamérica
}

\section{A new species of Albizia (Leguminosae: Mimosoideae) from Central America}

\author{
José Linares
}

\author{
Herbario Paul C. Standley, Escuela Agrícola Panamericana, P.O. Box 93, Tegucigalpa, \\ Honduras \\ Correspondencia: jlinares@zamorano.edu
}

\begin{abstract}
Resumen. Se describe e ilustra a Albizia xerophytica sp. nov., una nueva especie de El Salvador, Honduras y Nicaragua, de las selvas bajas caducifolias de la parte norte de Centroamérica y se discuten sus posibles afinidades taxonómicas.

Palabras clave: Leguminosae, Albizia, El Salvador, Honduras, Nicaragua, selvas bajas, Centroamérica.

Abstract. A new species, Albizia xerophytica sp. nov., is described and illustrated, and its taxonomic affinities are discussed. The tree has been collected from the low-land broadleaf forests of El Salvador, Honduras and Nicaragua of northern Central America.
\end{abstract}

Key words: Leguminosae, Albizia, El Salvador, Honduras, Nicaragua, Central America.

\section{Introducción}

Durante los dos últimos años, como resultado de exploraciones botánicas emprendidas por personal del Herbario Paul C. Standley (EAP) en las regiones semiáridas del centro de Honduras, se ha obtenido material de algunas especies poco conocidas en la región, así como de material que corresponde a especies no descritas anteriormente. Entre éstas sobresalen algunos especímenes de una Albizia no descrita anteriormente. Estas colecciones ponen de manifiesto la alta diversidad que los ecosistemas secos de la parte norte de Centroamérica poseen. Después de una detallada revisión morfológica de todos los especímenes de Albizia, de la región mencionada, disponibles en los Herbarios Nacional de México (Mexu), de la Escuela Agrícola Panamericana (EAP) y de la Universidad El Salvador (ITIC) resulta claro que los ejemplares mencionados arriba pertenecen a una especie no descrita con anterioridad y que se propone como nueva para la ciencia.

\section{Descripción}

Albizia xerophytica J. Linares, sp. nov. (Fig. 1).

Tipo: honduras. el Paraíso: Municipio Morocelí. Loc. Orillas de Quebrada Grande $\pm 3.9 \mathrm{~km}$ al NE de Morocelí por el camino hacia El Plan. 14 febrero 2002, J. L. Linares 5674, Gloria M. Linares, David Angulo, Siby Zabala, Rodolfo Rivera (holotipo, MEXU; isotipos, EAP).

Albizia adinocephala (Donn. Sm.) Britton et Rose similis, sed differt foliolis ellipticis vel oblongo-ellipticis, quasi glabris, latere abaxiali grandiore, et crescit in locis aridis.

Árboles de $5(-10) \mathrm{m}$ de alto; copa rala difusa, semidecidua; tallos de $10-15 \mathrm{~cm}$ de diámetro, corteza ligeramente rugosa, de apariencia lisa, gris-blanquecina en árboles jóvenes, gris claro, con líquenes, en árboles muy viejos; ramitas glabras con algunas lenticelas dispersas, pequeñas de menos de $1 \mathrm{~mm}$, elípticas a lineares, blancas, las ramitas florales verde oscuro, lisas, completamente glabras, herbáceas, aunque en el material de Honduras las ramitas florales son mayormente leñosas, finamente estriadas longitudinalmente; yemas seriales, con la inflorescencia desarrollándose de la yema distal. Las hojas más grandes de los especímenes con 1 a 2 , raramente 3 pares de pinnas y la pinna más larga con $4-6$ pares de folíolos, pinnas distales ligeramente mayores que las basales a subyúgales. Estípulas ca. 1 × $0.4 \mathrm{~mm}$, triangulares a subuladas, acuminadas, glabras. Peciolo $1-5.5 \mathrm{~cm}$, terete, glabro, con una glándula situada al final del pulvino o a menos de $10 \mathrm{~mm}$ de él, cupular, alargada en vista frontal de apariencia oblonga 2-3 x (0.5-) 0.8- $1 \mathrm{~mm}$, glándulas entre otros pares de pinnas o folíolos ausentes. Raquis glabro o muy esparcidamente pubescente en la cara adaxial, segmentos interfoliolares de 1.5-2 cm. Peciólulos 0.5-1 mm; los folíolos 1-5.3 x $0.6-2.4 \mathrm{~cm}$, asimétricamente elípticos a anchamente elípticos, subiguales a oblicuos, nunca rombiformes, base obtusa a subcordada, oblicua, borde liso, ápice agudo a obtuso a veces ligeramente retuso. Los folíolos subcoriáceos, conspicuamente bicoloros cuando frescos y moderadamente al secar, verde botella en el haz y verde claro en el envés, nervación broquidódroma, más clara y conspicua en el haz, al menos en estado fresco, completamente glabros en el haz y en el envés excepto por mechones de tricomas en la parte basal del envés en la axila 


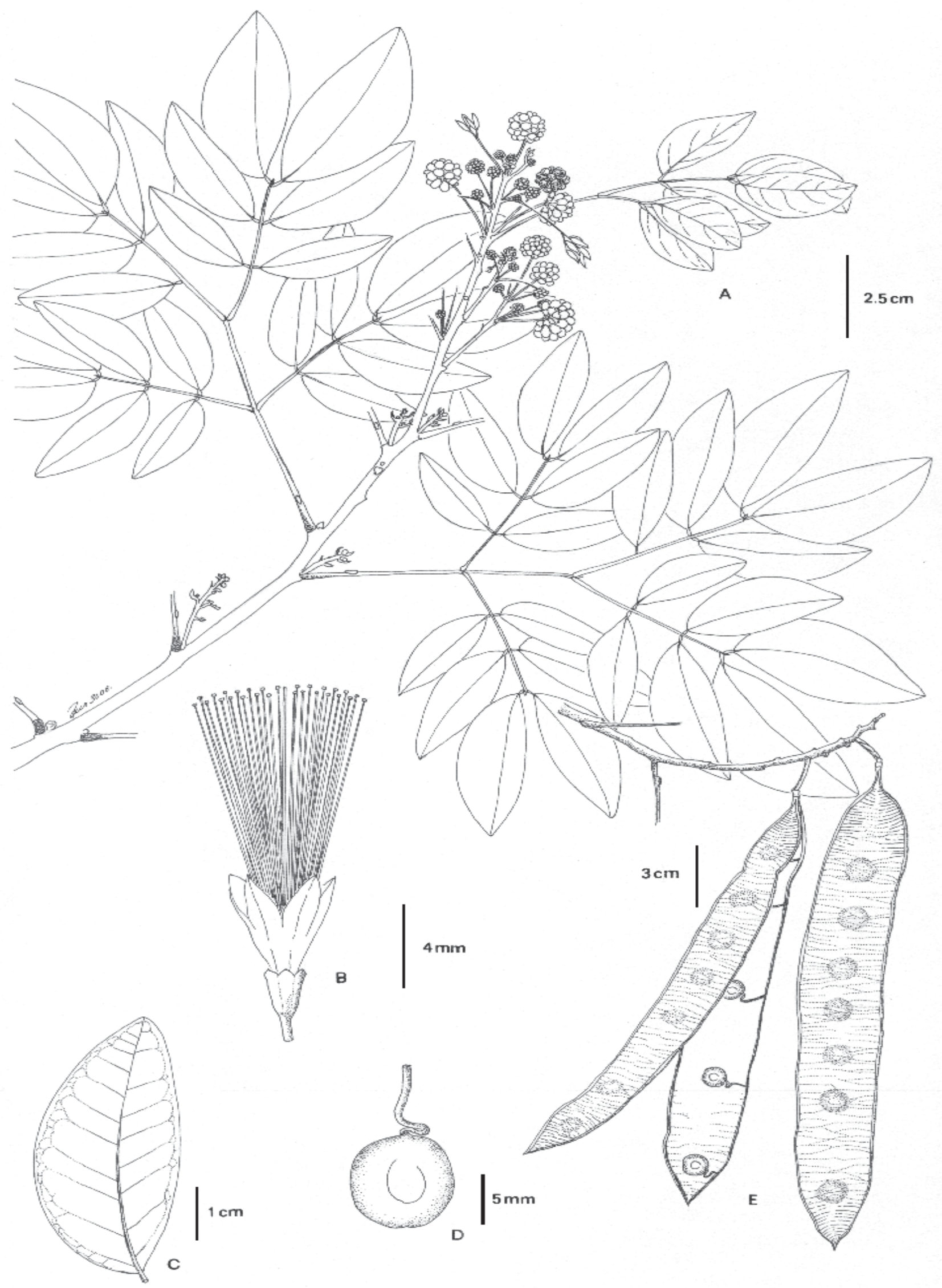

Figura 1. Albizia xerophytica sp. nov. A) Rama con inflorescencia. B) Flor. C) Foliolo terminal, mostrando el patrón de venación. D) Semilla. E) Frutos. A y C tomados de Linares et al. 6204, B tomado de Linares et al. 6263, D y E tomados de Linares et al. 5728. Todos en MEXU. 
de la primera nervadura en el lado próxima al raquis. Inflorescencias terminales racemosas (racimos de capítulos) con 1 a 5 pedúnculos por nudo, pedúnculos 3-6 cm de largo; capítulos globosos de 1.4-1.8 cm de diámetro, sin los filamentos, flores exteriormente glabras en la antesis, brácteas heteromórficas, las inferiores ovado-connadas de $<0.5 \mathrm{~mm}$ de largo las superiores espatuladas de ca. 1 x 0.4 mm, glabras a muy escasamente pubescentes; flores subiguales a iguales, pediceladas, pedicelo ca. $1 \mathrm{~mm}$; cáliz tubular a campanulado de $1.5 \times 1 \mathrm{~mm}$; corola ca. $5 \times 2 \mathrm{~mm}$, tubular o campanuladas 5-partida, lóbulos de 1-1.8 mm de largo, triangulares; androceo 1.2-1.5 cm de largo, blancos a blanco-verdosos. Legumbres 1-3 por capítulo, (9.3-) 12.321.5 x (2) $2.2-3.1 \mathrm{~cm}$, valvas oblongas, a menudo algo contraídas especialmente al final de las últimas semillas, lateralmente muy comprimidas, conspicuamente estipitadas, el estípite de $0.5-1 \mathrm{~cm}$ de largo, con un acumen de hasta 7 $\mathrm{mm}$, conspicuamente venoso reticuladas entre las suturas, dehiscentes por ambas suturas cuando maduros, semillas 5- 10 por fruto, funículo de $0.5-1.3 \mathrm{~cm}$, recto en la base, pero sigmoide en el ápice, semillas con el hilo transversal comprimidas lenticulares 6- 10 × 6-9 mm de orbiculares a oblongas, color crema o blanco marfil, con pleurograma en forma de herradura. Frutos dehiscentes por ambas suturas.

Distribución, hábitat y fenología. Albizia xerophytica crece en la región montañosa del norte de Centroamérica en pequeños valles cerrados o en laderas de montañas, siempre en selva baja caducifolia, en lugares con una estacionalidad muy marcada con épocas secas de hasta 7-8 meses de duración y con precipitaciones de $700 \mathrm{~mm}$ o menos; en las localidades encontradas hasta ahora, forma parte del estrato medio arbóreo o del estrato alto y crece tanto en lugares abiertos y rocosos como al lado de pequeños ríos o arroyos. Florece en febrero en El Salvador y en julio en Honduras y probablemente en Nicaragua y fructifica de enero a marzo en Honduras y Nicaragua (Fig. 2).

Paratipos. El Salvador. Santa Ana: Mpio. Metapán, Parque Nacional Montecristo, frente al camino del Apante, Elev. 1400 m, 14 febrero 2002, V. M. Martínez s.n (EAP, MeXu). Honduras. El Paraiso: Mpio. Morocelí, Quebrada Grande $\pm 4 \mathrm{Km}$ al E de Morocelí, por el camino a El Plan, $14^{\circ} 08^{\prime} 55^{\prime}$ ' N, 86 51' 30', O Elev. 740 m, 7 julio 2001, J. L. Linares, et al. 5406 (EAP, MEXU). Idem, 22 julio 2001, J. L. Linares 5492, 5494 (EAP, MEXU). Idem, 7 febrero 2002, J. L. Linares et al. 5635 (EAP, MEXU). Idem, 14 febrero 2002, J. L. Linares et al. 5674 (EAP, MEXU). Idem, 14 marzo 2002, J. L. Linares et al. 5728 (EAP, MEXU). Idem, 21 abril 2002, Linares 5905 (EAP, MEXu) Mpio. San Lucas. Alrededores de Tolobre \pm 15 al S de San Lucas, 7 agosto 2002, Linares 6231 (EAP, MEXU). Francisco MoraZÁn. Mpio. Sabanagrande. $\pm 1 \mathrm{~km}$ al S de Sabanagrande, a la orilla de la carretera Tegucigalpa-Choluteca (km 45), 18 julio 2002, Linares y R.N. Menéndez 6204 (EAP, MEXU). Idem, Linares y Menéndez 6263, 6264 (EAP, MEXu). YORO. Mpio. Olanchito, a $3 \mathrm{~km}$ OSO del pueblo de Arenal cerca del

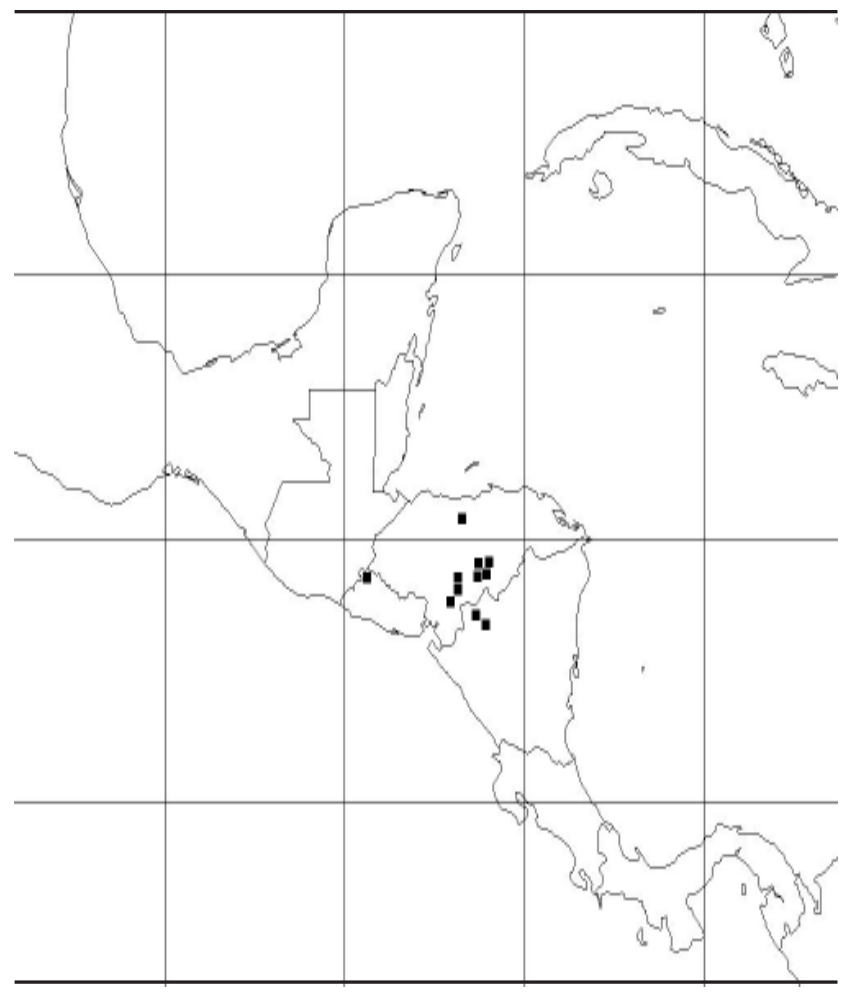

Figura 2. Mapa de distribución de Albizia xerophytica sp. nov. en Centroamérica.

camino a Jocon, 16 febrero1991, J.J. Hellin y C. E. Hughes 6 (EAP, MEXU). NicARAgua, Esteli: Mpio. Estelí, $24 \mathrm{~km}$ al N de Estelí, 1316’ N, 86²0'O. Elev. 700 m, 19 diciembre 1984, P.P. Moreno 25166 (MEXu). Mpio. San Juan Limay, a $8 \mathrm{~km}$ S del pueblo de San Juan de Limay, cerca del camino a San Jose Achupa, $13^{\circ} 7^{\prime}$ N, 88 37' W Alt. 620 m, 14 marzo 1991, C.E. Hughes et al 1435 (EAP, MEXU). Sin Mpio. Kukamoga km 167. Portal de Belén, $13^{\circ} 15^{\prime} \mathrm{N}, 86^{\circ} 21^{\prime} \mathrm{O}$, elev. 660 a 800 m, 1 agosto 1983, P.P. Moreno 21838 (MEXU). Nueva Segovia: Mpio. Los Planes, 16 septiembre 1985, $P$. P. Moreno 26436 (Mo).

Etimología: El epíteto específico alude al hábitat marcadamente xerofítico donde crece esta especie a diferencia de su pariente más cercano, A. adinocephala (Donn. Sm.) Britton et Rose, que crece en lugares mucho más húmedos.

\section{Discusión}

Albizia xerophytica ya había sido colectada en Honduras (Hellin y Hughes 6, depositado en EAP) y en la parte noroccidental de Nicaragua (Hughes et al. 1435, también en EAP) pero habían sido confundidos con Albizia adinocephala (Donn. Sm.) Britton et Rose en estudios anteriores (Barneby y Grimes, 1996). El tamaño, número y forma de los foliolos y de los frutos, distinguen a esta especie de Albizia adinocephala con la cual, probablemente esté relacionada. Albizia xerophytica posee siempre foliolos elípticos a ampliamente elípticos a diferencia de Albizia 
adinocephala que siempre los tiene romboidales, los foliolos de Albizia xerophytica son mucho más oblícuos, más grandes hacia el lado opuesto al raquis y esencialmente glabros, mientras que en Albizia adinocephala son más grandes hacia el lado del raquis y siempre son estrigulosos o densamente estrigulosos. Además, Albizia adinocephala parece crecer siempre en lugares mucho más húmedos. Por otra parte, esta última especie se distribuye desde el sureste de México hasta Panamá (Barneby y Grimes, 1996; Rico, 2001), y A. xerophytica parece tener una distribución mucho más restringida, limitada a las selvas bajas caducifolias del norte de Centroamérica. Otro rasgo distintivo de esta nueva especie es el hábito marcadamente arbustivo o de árbol pequeño que la diferencia de Albizia adinocephala que es, normalmente, un árbol de mas $10 \mathrm{~m}$ de alto. Al igual que Albizia adinocephala, A. xerophytica estaría ubicada en la sección Arthrosamanea pues presenta tallos con crecimiento determinado y sin yemas silépticas.

\section{Agradecimientos}

Al Dr. Fernando Chiang por la diagnosis en latín y sus comentarios al manuscrito, al Dr. Mario Sousa Sánchez y al Dr. George Pilz por su colaboración y ayuda, a Ramiro Cruz por la excelente ilustración.

\section{Literatura citada}

Barneby , R. C. y J. W. Grimes. 1996. Silk Tree, Guanacaste, Monkey's earring. A Generic System for the Synandrous Mimosaceae of the Americas. Part. I. Abarema, Albizia, and Allies. Memories of the New York Botanical Garden 74: 218- 221.

Rico, L. 2001. Albizia. In Flora de Nicaragua. W. D., Stevens, C. Ulloa U., A. Pool y O. M. Montiel (eds). Monographs in Systematic Botany from the Missouri Botanical Garden. 85: 1454- 1457. 